\title{
Determinants of Corporate Climate Change Mitigation Targets in Major United States Companies
}

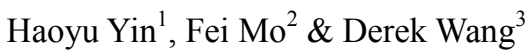 \\ ${ }^{1}$ China Energy Storage Alliance, Beijing, China \\ ${ }^{2}$ Beijing, China \\ ${ }^{3}$ Business School, China University of Political Science and Law, Beijing, China \\ Correspondence: Derek Wang, Business School, China University of Political Science and Law, Beijing, China. \\ E-mail: dwang@cupl.edu.cn
}

Received: October 31, 2016 Accepted: November 17, 2016 Online Published: February 3, 2017

doi:10.5539/jsd.v10n1p71 URL: http://dx.doi.org/10.5539/jsd.v10n1p71

\begin{abstract}
Setting greenhouse gas emission target is a critical step to meet the challenge of climate change. While the debate on global and national carbon emission targets has dominated every major climate change conference, little is known about how the firms set emission targets. Using a dataset on S\&P 500 companies in the United States, we investigate the determinants of firm-level climate change mitigation targets, including target adoption and target metric (intensity target vs. absolute target). We find that companies with larger size, higher growth, better innovation, weaker capital constraint, and higher government pressure are more likely to establish emission targets. Further, firm growth has a negative (positive) and significant association with the use of absolute (intensity) target. This may be due to the fact that intensity target can better accommodate growth than absolute target. Policymakers and corporate managers may resort to those determinant factors in designing climate change policies to induce desirable firm-level target-setting behaviors.
\end{abstract}

Keywords: climate change, corporate, carbon mitigation, target, target metric

\section{Introduction}

Climate change has been recognized as one of the greatest challenges for human society, as evidenced by the 2015 United Nations Climate Change Conference in Paris (COP21) and other preceding climate change summits. In order to keep the average global temperature increase to no more than $2^{\circ} \mathrm{C}$ above pre-industrial levels, we have to limit the emissions of greenhouse gas (GHG). A critical step of coping with GHG emissions is to set appropriate emission targets. Setting emission targets has always been the most important and contentious issue at every major conference on climate change. One of the earliest efforts to limit GHG emissions with binding targets is the 1997 Kyoto Protocol, which sets targets for industrialized countries with the aim to reduce GHG emissions by an average of 5.2\% below the 1990 levels by 2012. At COP21, almost all countries present, developed and developing countries alike, have come up with pledges to reduce specific amounts of GHG emissions by specified deadlines. A great amount of theoretical and empirical studies has been conducted to investigate the problems associated with setting country-level and region-level GHG emission targets (Philibert \& Pershing, 2001; Pizer, 2006; Lutsey \& Sperling, 2008).

While target setting has received a lot of attention at the global, national and subnational levels, the study of setting emission targets at the firm level is much less common. At the same time, as pointed out by Krabbe et al. (2015), striking a global or national agreement is a very slow and difficult process, as shown by the failure to create legally binding targets for major emitting countries at the Copenhagen Summit in 2009. As a result, there is a growing recognition among policymakers and researchers that the private sector may play a more proactive and significant role in tackling climate change. At COP21, John Danilovich, the general secretary of International Chamber of Commerce (ICC), indicates that "One thing is very clear: governments cannot do this alone...business action and engagement will be, without doubt, a central and defining part of the solution to the 
climate challenge." 1

In almost all corporate climate mitigation actions, target setting is usually an initial step and precedes the implementation of specific actions (Kolk \& Pinkse, 2004; Hoffman, 2007). Target setting can serve multiple important purposes, including as a motivator for carbon abatement actions, an indicator of mitigation commitments, guidelines to choose appropriate actions, and a standard to assess the progress achieved.

The forerunners in the corporate world that voluntarily set internal GHG emission targets are oil and gas companies. BP set up its first reduction target (a 10\% reduction from the 1990 emission levels by 2010) and publicly announced it in 2000 (Van den Hove, 2002). Other oil and gas companies have since followed suit. The practice of setting emission targets has then gradually spread to companies in other sectors, especially the energy-intensive ones (Dunn, 2002). As the awareness of climate risk increases, emission targets have proliferated in many industrial sectors. In the United States (U.S.), in the absence of national mandatory GHG emission targets, the U.S. Environmental Protection Agency (EPA) encourages companies to set emission targets through the voluntary Climate Leadership program, which was initially established in 2002 and replaced by the Center for Corporate Climate Leadership in 2011. Companies from various sector, such as the financial, construction and telecommunications, have participated in the program to obtain guidance on setting GHG emission targets and planning GHG mitigation measures.

In this paper, we investigate the drivers behind firm-level target setting among the biggest corporate emitters in the U.S. We examine the targets from two aspects: target adoption and target metric. Target adoption is a binary status indicating whether a company has an established target. Target metric refers to either absolute target or intensity target, both of which have been widely adopted by companies in practice. Absolute target sets a cap on the total GHG emissions regardless of the output of a company. Intensity target regulates the GHG emissions per unit of output. A company can use absolute and intensity targets simultaneously.

The drivers under study include companies' internal factors and external factors. The internal factors are company size, growth, innovation, capital constraint, and emission intensity. The external factors include pressure from government, market and physical climate change. Through this study, we aim to provide a systematic, holistic and comparative perspective on the strategies for target setting. Our study draws on a sample of 351 S\&P 500 companies in the U.S. The sample is extracted and constructed from the Carbon Disclosure Project (CDP: http://www.cdp.net), a non-profit organization based in London that maintains the largest database of firm-level climate change performance and policies. To the best of our knowledge, the CDP provides the most comprehensive and detailed data on companies' internal carbon management activities. The data enable us to look into the black box of emission target setting inside the major companies in the U.S. Given the size and the breadth of our sample and the representativeness of the companies in the sample, we believe that to a significant degree our study has captured the target setting strategies of the corporate world in the U.S. Prior literature has studied the determinant factors behind firms' environmental management practices. However, to the best of our knowledge, nothing has been done on the drivers behind climate change mitigation targets. Our study fills in the gap in the literature.

\section{Literature Review and Conceptual Framework}

In this section we first present the relevant literature. Then we elaborate on the features of target setting strategies that we aim to study and the potential drivers behind these features.

\subsection{Literature}

Our research is related to the broad category of literature on the corporate environmental and climate change management strategies. While the response to climate change has traditionally been delegated to national or regional entities, a burgeoning trend of research is exploring various aspects of corporate climate strategies. Prior literature has argued that companies' climate strategies will be a key driving force toward a low-carbon future (Kolk \& Pinkse, 2004; Levy, 2005). Further, empirical results point out that there is a growing willingness among business leaders to make bold investments on climate change mitigations (Persson \& Rockström, 2011), due to mounting stakeholder (e.g., governments, investors, consumers) pressure and increasing perceptions of opportunities associated with climate change. Indeed, empirical evidences have shown a spectrum of climate strategies employed by companies, including the disclosure of carbon footprints, the introduction of eco-design, the use of low-carbon energy, and the improvement of energy efficiency (Stanny, 2013; Tseng, Tan \& Siriban-Manalang, 2013; Rexhäuser and Löschel, 2015; Gerstlberger, Præst Knudsen \& Stampe, 2014; Cadez and

\footnotetext{
${ }^{1} \mathrm{http} / / / \mathrm{www}$. iccwbo.org/News/Articles/2015/Business-rallies-in-support-of-COP21-agreement-at-Le-Bourget/, accessed on September 18, 2016.
} 
Czerny, 2016), etc.

Despite the abundance of studies on corporate climate strategies, target setting, as a critical precondition to mitigation actions, has not received sufficient attention in the past. However, recently, there appears an emerging and rapidly growing stream of research on setting corporate emission targets, including the development of target setting methodology, the characterization of target setting behaviors, and the analysis of motivations behind target setting. Kolk and Pinkse (2004) use the CDP survey data in 2002 to analyze the corporate climate strategies of a broad sample of large multinational companies. They find that the target setting process displays great variations between firms in different sectors, and, overall, $51 \%$ of the respondents have targets to reduce or stabilize the direct GHG emissions. Gouldson and Sullivan (2013) investigate the efficacy and reliability of setting corporate emission targets as a response to climate change among the major supermarkets in the United Kingdom (U.K.). They find that the voluntary targets set by the supermarkets in the U.K. not only align with the goals of the U.K. government, but also are high likely to be achieved. Sullivan and Gouldson (2016) compare the target setting behavior of representative U.K. and U.S. retailers, and find U.K. companies tend to set more ambitious reduction targets. Krabbe et al. (2015) suggest that setting corporate emission targets is a critical step in attaining national and global climate goals, and proposes a methodology to derive the corporate targets. Using the CDP data, Ioannou, $\mathrm{Li}$ and Serafeim (2015) find that the completion rate of carbon reduction targets is positively affected by both the provision of monetary incentives and the difficulty of the targets.

\subsection{Target-Setting Characteristics}

In this section we describe the two salient features of targets that we aim to study, i.e., target adoption and target metric.

Target Adoption: This refers to the binary status of whether or not a company has an established target for reducing GHG emissions. Companies may have diverse motives of target setting. Basically, setting an emission target provides a company with a clear criterion to gauge the success of its climate change efforts. Targets can also serve to motivate and pressure a company to take actions. In addition, the adoption of targets may serve as a means for companies to demonstrate to the public their climate friendliness.

Target Metric: The target metric refers to the choice between intensity and absolute measures by a company in benchmarking its GHG emission actions. The absolute target sets a cap on the GHG emissions at a specific time point in the future, regardless of the amount of output of a company. The intensity target puts a limit on the emission per unit of output. Both absolute and intensity targets for environmental purposes are common in reality. The Corporate Average Fuel Economy standards in the U.S. can be regarded as an intensity target and cap-and-trade scheme for sulphur dioxide emissions is on an absolute basis. There have been a great amount of discussions on the advantages and drawbacks of both absolute and intensity metrics. Since the intensity target can tie total emission to economic activity, it has been argued that it provides a more flexible governing framework to accommodate growth (Fischer \& Springborn, 2011). Indeed, at the country level, fast-growing countries like China and India have resorted to carbon intensity of GDP rather than absolute terms in Copenhagen Accord and COP21. But others have argued that the uncertain total emissions pose a potential problem for climate change adaption and intensity targets may serve to "wrap up a weak environmental policy and make it look better" (Dudek \& Golub, 2003). Some companies employ both absolute and intensity targets.

\subsection{Drivers for Target Setting}

In this section we outline the potential drivers for setting the GHG emission targets. The factors can be either internal or external to the companies. The internal factors include a company's size, growth, innovation, capital constraint, and emission intensity. The external factors include pressure from government, market, and physical climate change. Below we describe the definitions of the factors and the rationale for including them in this study.

\subsubsection{Internal Drivers of Targets}

Firm Size: Various studies have indicated that larger companies are more likely to implement environmental management practices, such as the certification of ISO14001 (Nakamura, Takahashi \& Vertinsky, 2001) and end-of-pipe pollution control technologies (Demirel \& Kesidou, 2011), than smaller ones. Different rationales have been proposed to explain the positive association between company size and environmental proactivity. Nakamura et al. (2001) argue that larger companies may benefit from economies of scale and are more capable of devoting resources to environmental practices. Bowen (2002) suggests that larger companies have societal visibility and hence bear greater pressure from regulators and the general public to comply with certain environmental standards. An alternative view argues that the sign (i.e., positive or negative) of an association depends on the specific environmental initiatives being implemented (Sharma \& Henriques, 2005). While larger 
companies may undertake pollution control and eco-efficiency initiatives in a more efficient manner, smaller companies are more flexible in developing disruptive environmental innovations (Sharma \& Henriques, 2005). To the best of our knowledge, no paper has touched on the relationship between firm size and emission targets.

Firm Growth: Russo and Fouts (1997) debate that companies in high-growth industries are more likely to benefit from improved environmental performance than those in low-growth industries, because high-growth is associated with both higher prospect of return and better tolerance of risk from the environmental initiatives. Therefore, we conjecture that companies with high growth potentials are more likely to adopt targets. Moreover, there are a lot of debates at the national level on how to set emission targets to accommodate economic growth. Intensity target is proposed as a mechanism which can balance environmental goals and national economic growth and is more flexible than absolute target, since there is no cap in intensity target restraining the total amount of emission as does that in absolute target (Dudek \& Golub, 2003). Similar logic can be applied to firm-level targets: intensity target is linked to per unit of output of a company, the latter in turn reflects the growth rate of that company, therefore, intensity target may balance the environmental target of a company and the growth of a company. Hence, firms with high growth may favor intensity target.

Innovation: It has long been argued that companies with stronger research and development (R\&D) capabilities are more likely to benefit from environmental initiatives, especially the initiatives aiming to enhance eco-efficiency (Anton, Deltas \& Khanna, 2004; Martin, Muûls, de Preux, \& Wagner, 2012). This is because more innovative companies are more adept in undertaking process and product innovation to reduce per unit energy and material input. Hence, innovation may be positively related to the use of target.

Capital Constraint: Investments in environmental protection actions, just like any other investments, are invariably constrained by companies' financial status. A company under heavy capital constraint may not be able to allocate sufficient resources to climate strategies, and hence is likely to eschew emission targets in the first place.

Emission Intensity: A company's emission intensity is likely to impact its decision on setting emission targets. Companies with high emission intensities are likely to face more pressure from stakeholders such as regulators and consumers than their counterparts with low emission intensities. Therefore, a company with high emission intensity may be more proactive in adopting emission targets.

\subsubsection{External Drivers of Targets}

Government Pressure: It has long been argued that government pressure is a major driving force behind the companies' environmental practices (Anton et al., 2004). The pressure usually takes the form of existing and potential environmental regulations. In the U.S., debates on limiting GHG emissions via regulatory measures have been going on for years. Even though no legally binding national targets have been set so far, sub-national programs have emerged and expanded (e.g., Regional Climate Change Initiative, California Cap-and-Trade Program, and Quebec Cap-and-Trade Program).

Market Pressure: Another important determinant of companies' environmental conduct is the attitude of the market (Anton et al., 2004). The market factors include reputation and changing consumer behavior. The environmentally conscious customers are increasingly reluctant to purchase products and services from a company with tainted environmental profile.

Climate Pressure: Climate pressure refers to pressure of physical impacts of climate change, which can affect business operations. Relevant physical impacts include change in mean and extreme temperatures, change in precipitation pattern, rise of sea level, and increased activities of tropical cyclones. Such physical phenomena of climate change may impact the business operations of a company both directly and indirectly. For instance, Coca-Cola acknowledges that climate change, such as droughts, poses great threats to the company's operations and economic bottom-line. ${ }^{2}$ In response, the company has started to phase out diesel fleet with renewable trucks, improve energy efficiency of its manufacturing process, and redesign its products to reduce carbon footprints.

\section{Data and Variables}

This section describes the data source on target setting and the method of constructing the relevant variables from the data.

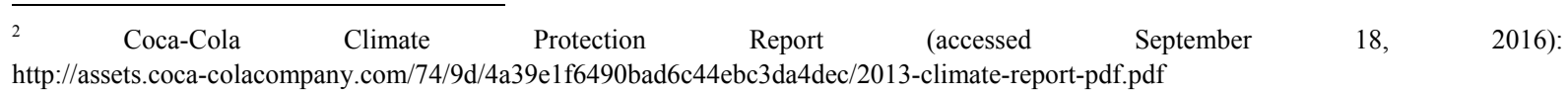




\subsection{Data Source}

The data used in this study are extracted from the CDP database (http://www.cdp.net) and COMPUSTAT. The CDP builds the world's largest database regarding corporate performance in relation to climate change. The goal of CDP is to provide relevant tools and information to companies, investors and policymakers to manage climate change risks. The CDP collects the data through an annual survey sent to major companies worldwide at the end of each calendar year. The survey is very detailed, with more than 100 questions covering topics like management attitude toward climate change, incentive policy for carbon abatement, GHG emission level, and abatement activities implemented. For each question, CDP also provides very detailed reporting guidance on the answer, such as the type of information to be included and the format to be used. For instance, when CDP asks the respondent to report the annual monetary saving from GHG abatement initiatives, it states that "enter the amount of monetary savings per year expected from the initiative once it is fully operational. The number ... should be entered in full and without commas... Where savings occur on a non-annual basis, please average out so that an annual figure can be provided." The companies are requested to submit the answers via an online system by the end of May each year. The CDP then analyzes the responses and assigns two scores to each report. The disclosure score measures the reporting quality and the performance score measures the climate change performance. The report itself and the two scores are published at the CDP website. The CDP data set has been used by several previous studies, such as Kolk and Pinkse (2004) and Yu, Wang, Li and Shi (2016). The company characteristic data are obtained from COMPUSTAT.

\subsection{Variables}

We collect data on target variables from the CDP survey in 2013. The CDP survey asks a company if it has an emission reduction target that was active (ongoing or reaching completion) in the reporting year. The yes/no answer to the question yields a binary variable for target adoption. Then the company is asked to specify the metric of the target if there is one. From the answers we can derive the target metric variable.

We construct government pressure, market pressure and climate pressure variables with the answers to an array of questions in the CDP database. First, the CDP asks the respondents to report assessment of a wide array of regulatory tools, including international agreements, air pollution limits, carbon taxes, cap and trade schemes, emission reporting obligations, fuel/energy taxes, and product efficiency standards. For each type of regulatory tool, the companies are requested to report the magnitude of the impact of regulation, which is rated by a 5-level scale from low to high. We let the low magnitude take the value of 1 , and the high magnitude take the value of 5, and all other magnitude levels in between. Then we take the average magnitude of all types of regulatory tools as the proxy for government pressure. Market pressure and climate pressure are constructed in a similar manner.

We collect relevant firm characteristic data from COMPUSTAT. We use the natural logarithm of total assets (item 6) to proxy the firm size. The company growth is measured as the sales (item 12) growth rates for the companies averaged for the past three years at the setup date of the target. A company's capital constraint is measured by its leverage, which is the ratio between long-term debt (item 9) and total assets. We use the R\&D intensity, measured by the ratio between R\&D expense (item 46) and sale, to proxy a company's innovation capability. Following the common practice in many previous studies, we replace missing R\&D expense in COMPUSTAT with zero. Emission intensity is given as the ratio between total emissions and sales.

In running the empirical models, we need to take the time frame of the targets into consideration. Ideally, the potential determinant factors of the target adoption and target metric should be the factors at or prior to the time when the target was set up. Since CDP does not include the date when the target was established, we need to infer the target setup date from the completion time of the target. For instance, McCormick \& Company reported in the CDP data for 2013 that the company had a target that aimed to abate $5 \%$ of its emissions by 2015 and further reported that the time period for completing the target had elapsed by $50 \%$ in 2012 . Therefore, we can infer that the target was established in 2009. But for a certain number of companies with their targets $100 \%$ completed, it is impossible to derive setup dates of targets using the above-mentioned method. For those companies, we use the variables one year before the reporting year in the regression. Also, we only have the government pressure, market pressure, and climate pressure data of the reporting year. Therefore, we use them in contemporaneous measure in all regressions.

In addition, we control for the potential of being affected by norms and trends of a particular industry through industry dummies and the time through year dummies. The industry dummies are created based on the two-digit Global Industry Classification Standard (GICS) codes. The year dummies are created based on the year when a particular target was set up.

Table 1 presents the summary statistics for the 351 companies. Panel A reports the distribution of the companies 
and adoption rates of targets by GICS codes. Overall, $74.64 \%$ (100\%-25.36\%) of the companies have established emission targets. Absolute target and intensity target are almost equally common, with each of them being adopted by around $30 \%$ of the companies. Our sample covers all 10 sectors under GICS. Among the sectors, information technology sector has the highest ratio of companies without emission targets (41.27\%), followed by the energy sector $(37.50 \%)$. Panel B presents the mean, standard deviation, $25^{\text {th }}$ and $75^{\text {th }}$ quartiles for the key variables used in our study.

Table 1 . Targets and summary statistics

Panel A: Distribution of target adoption and metrics by industry

\begin{tabular}{|c|c|c|c|c|c|c|c|c|c|}
\hline \multirow[b]{2}{*}{ GICS sector } & \multicolumn{2}{|c|}{ No target } & \multicolumn{2}{|c|}{ Absolute target } & \multicolumn{2}{|c|}{ Intensity target } & \multicolumn{2}{|c|}{ Absolute \& intensity targets } & \multirow[b]{2}{*}{ Total } \\
\hline & \# of firms & Percentage (\%) & \# of firms & Percentage (\%) & \# of firms & Percentage (\%) & \# of firms & Percentage (\%) & \\
\hline Consumer Discretionary & 9 & 16.98 & 15 & 28.30 & 20 & 37.74 & 9 & 16.98 & 53 \\
\hline Consumer Staples & 6 & 17.14 & 5 & 14.29 & 17 & 48.57 & 7 & 20.00 & 35 \\
\hline Energy & 6 & 37.50 & 2 & 12.50 & 5 & 31.25 & 3 & 18.75 & 16 \\
\hline Financials & 12 & 26.09 & 24 & 52.17 & 6 & 13.04 & 4 & 8.70 & 46 \\
\hline Health Care & 7 & 24.14 & 13 & 44.83 & 7 & 24.14 & 2 & 6.90 & 29 \\
\hline Industrials & 10 & 20.00 & 12 & 24.00 & 22 & 44.00 & 6 & 12.00 & 50 \\
\hline Information Technology & 26 & 41.27 & 17 & 26.98 & 15 & 23.81 & 5 & 7.94 & 63 \\
\hline Materials & 6 & 22.22 & 5 & 18.52 & 9 & 33.33 & 7 & 25.93 & 27 \\
\hline \multicolumn{10}{|l|}{ Telecommunication } \\
\hline Services & 0 & 0.00 & 2 & 40.00 & 2 & 40.00 & 1 & 20.00 & 5 \\
\hline Utilities & 7 & 25.93 & 13 & 48.15 & 3 & 11.11 & 4 & 14.81 & 27 \\
\hline Overall & 89 & 25.36 & 108 & 30.77 & 106 & 30.20 & 48 & 13.68 & 351 \\
\hline
\end{tabular}

Panel B: Summary statistics

\begin{tabular}{|c|c|c|c|c|}
\hline & Mean & Standard deviation & 25th Percentile & 75th Percentile \\
\hline Firm_Size & 9.75 & 1.50 & 8.82 & 10.61 \\
\hline Firm_Growth & -0.03 & 0.12 & -0.07 & 0.02 \\
\hline Innovation & 0.06 & 0.08 & 0.01 & 0.09 \\
\hline Capital_Constraint & 0.22 & 0.14 & 0.11 & 0.31 \\
\hline Emission_Intensity & 3.94 & 1.95 & 2.77 & 5.07 \\
\hline Government_Pressure & 0.46 & 0.54 & 0.00 & 0.75 \\
\hline Market_Pressure & 0.26 & 0.38 & 0.00 & 0.38 \\
\hline Climate_Pressure & 0.46 & 0.58 & 0.00 & 0.64 \\
\hline
\end{tabular}

\section{Methods and Results}

\subsection{Target Adoption}

We first investigate the relationship between company characteristics and a company's target adoption decision. We estimate a binary probit regression model in which the dependent variable Target_Adoption takes the value of 1 if the firm sets up a target of any metric, and 0 otherwise. The probit model is represented as follows,

$$
\operatorname{Prob}\left(\text { Target_Adoption }_{i}=1\right)=\Phi\left(\alpha+X_{i} \beta_{X}+Y_{i} \beta_{Y}+C_{i} \beta_{C}+\varepsilon_{i}\right) .
$$

In equation (1), the subscript $i$ denotes company $i, \Phi$ is the standard cumulative normal distribution, $\alpha$ is an intercept, $X_{i}$ is a vector of covariates corresponding to the characteristics of company $i$ (Firm_Size, Firm_Growth, Innovation, Capital_Constraint, and Emission_Intensity), $Y_{i}$ is a vector of covariates corresponding to the external factors of company $i$ (Government_Pressure, Market_Pressure, and Climate_Pressure), $C_{i}$ represents a vector of control variables (industry and year dummies), and $\beta_{X}, \beta_{Y}$ and $\beta_{C}$ represent the unknown coefficients we aim to estimate with maximum likelihood.

Table 2 presents the estimated coefficients and marginal effects of the target adoption regression in (1). The purpose of reporting the marginal effects for all the variables is to put the magnitude of likelihood increase in perspective. The marginal effects are calculated as the change in predicted probability when the covariate varies by one standard deviation (from 0.5 standard deviation below the mean value to 0.5 standard deviation above the mean value), with all other covariates fixed at the mean values. For instance, a one standard deviation increase in government pressure is associated with a $14 \%$ increase in the probability of adopting emission targets $(18.85 \%$ 
relative to the baseline probability of $74.64 \%$ shown at the bottom at the table).

Among the internal factors, the coefficient and marginal effect for Firm_Size are positive and significant at the $\mathrm{p}<0.01$ level. The coefficients and marginal effects for Firm_Growth and Innovation are positive and significant at the $\mathrm{p}<0.1$ level. Capital_Constraint is negatively associated with Target_Adoption at $\mathrm{p}<0.1$. Among the external factors, we find the coefficient and marginal effect for government pressure are positive and significant at the $p<0.05$ level. Hence government pressure in the form of regulation or threat of regulation can stimulate the use of emission targets. We find relatively weak evidence of market pressure and climate pressure on the likelihood of target adoption. Overall, the results show that companies with larger size, higher growth, better innovation, weaker capital constraint, and higher government pressure are more likely to establish emission targets.

Table 2. Determinants of target adoption

\begin{tabular}{|c|c|c|}
\hline & Coefficient & Marginal effect \\
\hline Intercept & $\begin{array}{l}-2.6880^{* * *} \\
(0.6204)\end{array}$ & \\
\hline \multicolumn{3}{|l|}{ Internal Factors } \\
\hline Firm_Size & $\begin{array}{l}0.1966^{* * *} \\
(0.0594)\end{array}$ & 0.0548 \\
\hline Firm_Growth & $\begin{array}{l}1.1000 * \\
(0.5514)\end{array}$ & 0.3065 \\
\hline Innovation & $\begin{array}{l}1.4710^{*} \\
(0.8360)\end{array}$ & 0.4097 \\
\hline Capital_Constraint & $\begin{array}{l}-1.2198 * \\
(0.6158)\end{array}$ & -0.3337 \\
\hline Emission_Intensity & $\begin{array}{r}-0.0001 \\
(0.0001)\end{array}$ & 0.0000 \\
\hline \multicolumn{3}{|l|}{ External Factors } \\
\hline Government_Pressure & $\begin{array}{l}0.5050 * * \\
(0.2360)\end{array}$ & 0.1407 \\
\hline Market_Pressure & $\begin{array}{r}0.2584 \\
(0.3442)\end{array}$ & 0.0720 \\
\hline Climate_Pressure & $\begin{array}{r}0.2189 \\
(0.2264)\end{array}$ & 0.0610 \\
\hline $\begin{array}{l}\text { Industry fixed effect } \\
\text { Year fixed effect }\end{array}$ & $\begin{array}{l}\text { Yes } \\
\text { Yes }\end{array}$ & \\
\hline $\begin{array}{l}\text { Prob(Target adoption) (\%) } \\
\text { Target adoptions } \\
\text { Number of Observations }\end{array}$ & $\begin{array}{r}74.6439 \\
262 \\
351\end{array}$ & \\
\hline Pseudo R-squared & 0.2352 & \\
\hline
\end{tabular}

Standard errors are in parentheses

${ }^{*} \mathrm{p}<0.1 ; * * \mathrm{p}<0.05 ; * * * \mathrm{p}<0.01$.

\subsection{Target Metrics}

We examine the impact of internal and external factors on the target metrics using multinomial logit regression. In this case there are four categories, e.g., no target, absolute target only, intensity target only, and both absolute and intensity targets. Note that absolute and intensity targets are not mutually exclusive so the last category is needed to represent the firms that adopt both. The multinomial logit regression allows us to discern the determinants of different target metrics simultaneously. The model is given as follows.

$$
\operatorname{Prob}\left(\text { Target_Metric }_{i}=j\right)=\frac{\exp \left(\beta_{j} X_{i}\right)}{\sum_{k=1}^{4} \exp \left(\beta_{k} X_{i}\right)},
$$

where $j$ is 1 if no target, 2 if absolute target, 3 if intensity target, and 4 if both absolute and intensity targets. The category of no target is omitted and all coefficients are measured relative to this category. Table 3 reports the multinomial logit regression results. We report the results for absolute target and intensity target only. 
Table 3. Determinants of target metric

\begin{tabular}{lcc}
\hline & Absolute Target & Intensity Target \\
\hline Intercept & $-1.5022^{* *}$ & -0.9155 \\
& $(0.6557)$ & $(0.5516)$ \\
Internal Factors & & \\
Firm_Size & $0.1918^{* * *}$ & 0.1057 \\
& $(0.0595)$ & $(0.0632)$ \\
Firm_Growth & $-1.8810 * * *$ & $0.3193 * *$ \\
& $(0.6630)$ & $(0.1567)$ \\
Innovation & 0.9810 & 0.0065 \\
& $(1.2549)$ & $(0.2318)$ \\
Capital_Constraint & 0.9975 & 0.2551 \\
& $(0.5506)$ & $(0.1804)$ \\
Emission_Intensity & -0.0620 & 0.0011 \\
& $(0.0429)$ & $(0.0406)$ \\
External Factors & & \\
Government_Pressure & 0.2891 & -0.0010 \\
& $(0.2108)$ & $(0.0351)$ \\
Market_Pressure & -0.0764 & 0.0026 \\
& $(0.1887)$ & $(0.0911)$ \\
Climate_Pressure & 0.1103 & 0.0026 \\
& $(0.2057)$ & $(0.0930)$ \\
Industry fixed effects & Yes & \\
Year fixed effects & Yes & \\
Number of Observations & 351 & \\
Pseudo R-squared & 0.1948 & \\
\end{tabular}

Standard errors are in parentheses

${ }^{*} \mathrm{p}<0.1 ; * * \mathrm{p}<0.05 ; * * * \mathrm{p}<0.01$.

Firm_Size is positively significantly related to the probability of using absolute target relative to the case of no target at the $\mathrm{p}<0.01$ level. Its association with intensity target is also positive but not significant. Furthermore, Firm_Growth is positively (negatively) significantly associated with the probability of employing intensity (absolute) target. The result is in line with the conjecture that high-growth firms are inclined to use intensity target, because it allows the firms to control emission and accommodate economic growth simultaneously. The argument that intensity target balances emission and growth has been made for countries and our result indicates that firms appear to have embraced the same argument for themselves. But at the same time, we would like to note that intensity target leads to greater uncertainty in total emissions as compared to absolute target. So policymakers may need to keep a keen eye on those firms that use intensity target. Also, we note that Emission_Intensity negatively affects the use of absolute target, but the effect is not significant. Innovation and Capital_Constraint are positively associated with both targets, but the results are not significant. The external factors do not display significant associations with either type of targets. Overall, Firm_Size and Firm_Growth display significant effects on target metrics while the other factors do not show significance.

\section{Discussions and Conclusions}

In this paper we investigate the determinants behind the use of GHG emission targets among U.S. S\&P 500 companies. Target setting is a critical initial step in GHG mitigation. We find that companies with larger size, higher growth, better innovation, weaker capital constraint, and higher government pressure are more likely to set emission targets. Moreover, high-growth firms are more likely to use intensity targets. We do not find any significant impact from market pressure and climate pressure on target adoption. Our study complements the literature on the drivers behind firms' environmental actions (Anton et al., 2004).

Policymakers and firm managers should consider the aforementioned factors and their impacts on target characteristics in order to induce desirable target-setting behaviors in the corporate world. Among the major companies sampled in our study, there are still $25 \%$ of companies without emission targets. Going forward, 
policymakers should try to increase the adoption of emission targets among the firms. For instance, to encourage the use of emission targets, policymakers may seek ways to create or strengthen governmental pressure on the firms in the form of regulatory measures. Hard measures such as carbon tax or emission cap may not be viable in the short term. But there are ways, such as mandatory emission reporting and even simple threat of stringent regulation, that policymakers can leverage to boost the pressure on firms (Anton et al., 2004). In promulgating the emission targets, policymakers may also pay special attention to smaller, low-growth, less innovative firms, which have been found to be less likely to use emission targets. Moreover, the policymakers should be cautious of the emissions from high-growth firms, since those firms are likely to use intensity metric to control GHG emissions and no cap is imposed on the total emissions.

\section{References}

Anton, W. R. Q., Deltas, G., \& Khanna, M. (2004). Incentives for environmental self-regulation and implications for environmental performance. Journal of Environmental Economics and Management, 48(1), 632-654. http://dx.doi.org/10.1016/j.jeem.2003.06.003

Bowen, F. E. (2002). Does size matter?. Business and Society, 41(1), 118.

Cadez, S., \& Czerny, A. (2016). Climate change mitigation strategies in carbon-intensive firms. Journal of Cleaner Production, 112, 4132-4143. http://dx.doi.org/10.1016/j.jclepro.2015.07.099

Demirel, P., \& Kesidou, E. (2011). Stimulating different types of eco-innovation in the UK: Government policies $\begin{array}{llll}\text { and firm motivations. Ecological Economics, } & \text { 70(8), }\end{array}$ http://dx.doi.org/10.1016/j.ecolecon.2011.03.019

Dudek, D., \& Golub, A. (2003). "Intensity" targets: pathway or roadblock to preventing climate change while enhancing economic growth?. Climate Policy, 3, S21-S28. http://dx.doi.org/10.1016/j.clipol.2003.09.010

Dunn, S. (2002). Down to business on climate change. Greener Management International, 2002(39), 27-41. http://dx.doi.org/10.9774/GLEAF.3062.2002.au.00005

Fischer, C., \& Springborn, M. (2011). Emissions targets and the real business cycle: Intensity targets versus caps or taxes. Journal of Environmental Economics and Management, 62(3), 352-366. http://dx.doi.org/10.1016/j.jeem.2011.04.005

Gerstlberger, W., Præst Knudsen, M., \& Stampe, I. (2014). Sustainable development strategies for product innovation and energy efficiency. Business Strategy and the Environment, 23(2),131-144. http://dx.doi.org/10.1002/bse.1777

Gouldson, A., \& Sullivan, R. (2013). Long-term corporate climate change targets: What could they deliver? Environmental Science \& Policy, 27, 1-10. http://dx.doi.org/10.1016/j.envsci.2012.11.013

Herzog, T., Baumert, K. A., \& Pershing, J. (2006). Target: Intensity. An analysis of greenhouse gas intensity targets. Washington, DC: World Resources Institute. Retrieved from http://pdf.wri.org/target_intensity.pdf

Hoffman, A. J. (2007). Carbon strategies: How leading companies are reducing their climate change footprint. Ann Arbor, MI: University of Michigan Press.

Ioannou, I., Li, S. X., \& Serafeim, G. (2016). The Effect of Target Difficulty on Target Completion: The Case of Reducing Carbon Emissions. The Accounting Review, 91(5),1467-1492. http://dx.doi.org/10.2308/accr-51307

Kolk, A., \& Pinkse, J. (2004). Market strategies for climate change. European Management Journal, 22(3), 304-314. http://dx.doi.org/10.1016/j.emj.2004.04.011

Krabbe, O., Linthorst, G., Blok, K., Crijns-Graus, W., van Vuuren, D. P., Höhne, N., ... Pineda, A. C. (2015). Aligning corporate greenhouse-gas emissions targets with climate goals. Nature Climate Change, 5(12), 1057-1060. http://dx.doi.org/10.1038/nclimate2770

Levy, D. L. (2005). Business and the evolution of the climate regime: The dynamics of corporate strategies. In D. L. Levy \& P. J. Newell (Eds.), The Business of Global Environmental Governance (pp. 73-104). Cambridge, MA: MIT Press.

Lutsey, N., \& Sperling, D. (2008). America's bottom-up climate change mitigation policy. Energy Policy, 36(2), 673-685. http://dx.doi.org/10.1016/j.enpol.2007.10.018

Martin, R., Muûls, M., de Preux, L. B., \& Wagner, U. J. (2012). Anatomy of a paradox: Management practices, organizational structure and energy efficiency. Journal of Environmental Economics and Management, 63(2), 
208-223. http://dx.doi.org/10.1016/j.jeem.2011.08.003

Nakamura, M., Takahashi, T., \& Vertinsky, I. (2001). Why Japanese firms choose to certify: a study of managerial responses to environmental issues. Journal of Environmental Economics and Management, 42(1), 23-52.

Persson, Å., \& Rockström, J. (2011). Business leaders. Nature Climate Change, 1(9), 426-427.

Philibert, C., \& Pershing, J. (2001). Considering the options: climate targets for all countries. Climate Policy, 1(2), 211-227. http://dx.doi.org/10.1016/S1469-3062(01)00003-1

Pizer, W. A. (2006). The evolution of a global climate change agreement. The American economic review, 96(2). 26-30. http://dx.doi.org/10.1257/000282806777211793

Rexhäuser, S., \& Löschel, A. (2015). Invention in energy technologies: Comparing energy efficiency and renewable energy inventions at the firm level. Energy Policy, 83, 206-217. http://dx.doi.org/10.1016/j.enpol.2015.02.003

Russo, M. V., \& Fouts, P. A. (1997). A resource-based perspective on corporate environmental performance and profitability. Academy of Management Journal, 40(3), 534-559. http://dx.doi.org/10.2307/257052

Sharma, S., \& Henriques, I. (2005). Stakeholder influences on sustainability practices in the Canadian forest products industry. Strategic Management Journal, 26(2), 159-180. http://dx.doi.org/10.1002/smj.439

Stanny, E. (2013). Voluntary disclosures of emissions by US firms. Business Strategy and the Environment, 22(3), 145-158. http://dx.doi.org/10.1002/bse. 1732

Sullivan, R., \& Gouldson, A. (2016). Comparing the climate change actions, targets and performance of UK and US retailers. Corporate Social Responsibility and Environmental Management, 23(3), 129-139. http://dx.doi.org/10.1002/csr.1364

Tseng, M. L., Tan, R. R., \& Siriban-Manalang, A. B. (2013). Sustainable consumption and production for Asia: sustainability through green design and practice. Journal of Cleaner Production, 40, 1-5. http://dx.doi.org/10.1016/j.jclepro.2012.07.015

Van den Hove, S., Le Menestrel, M., \& De Bettignies, H. C. (2002). The oil industry and climate change: strategies and ethical dilemmas. Climate Policy, 2(1), 3-18. http://dx.doi.org/10.1016/S1469-3062(02)00008-6

Yu, Y., Wang, D. D., Li, S., \& Shi, Q. (2016). Assessment of US firm-level climate change performance and strategy. Energy Policy, 92, 432-443. http://dx.doi.org/10.1016/j.enpol.2016.02.004

\section{Copyrights}

Copyright for this article is retained by the author(s), with first publication rights granted to the journal.

This is an open-access article distributed under the terms and conditions of the Creative Commons Attribution license (http://creativecommons.org/licenses/by/4.0/). 